\title{
Chronic Chagas Cardiomyopathy Patients and Resynchronization Therapy: a Survival Analysis
}

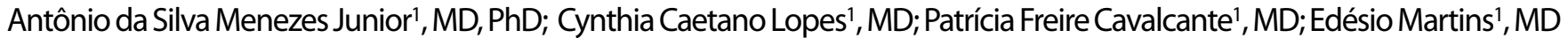

DOI: 10.21470/1678-9741-2017-0134

\begin{abstract}
Introduction: Chagas disease represents an important health problem with socioeconomic impacts in many Latin-American countries. It is estimated that $20 \%$ to $30 \%$ of the people infected by Trypanosoma cruzi will develop chronic Chagas cardiomyopathy (CCC), which is generally accompanied by heart failure (HF). Cardiac resynchronization therapy (CRT) may be indicated for patients with $\mathrm{HF}$ and electromechanical dysfunctions.

Objective: The primary endpoint of this study was to analyze the response to CRT in patients with CCC, while the secondary endpoint was to estimate the survival rates of CRT responder patients.

Methods: This is an observational, cross-sectional and retrospective study. The records of $\mathbf{5 0}$ patients with CRT pacing devices implanted between June 2009 and March 2017 were analyzed. For statistical analyses, Pearson's correlation was used
\end{abstract}

along with Student's t-test, and survival was analyzed using the Kaplan-Meier method. A $P$ value of $<0.05$ was considered significant.

Results: Out of $\mathbf{5 0}$ patients, $\mathbf{5 6 \%}$ were male, with a mean age of $63.4 \pm 13.3$ years and an average CRT duration of $61.2 \pm 21.7$ months. The mean QRS duration was $150.12 \pm 12.4 \mathrm{~ms}$ before and $116.04 \pm 2.2 \mathrm{~ms}$ after the therapy $(P<0.001)$. The mean left ventricular ejection fractions (LVEF) were $29 \pm 7 \%$ and $39.1 \pm 12.2 \%$ before and after CRT, respectively $(P<0.001)$. A total of $35(70 \%)$ patients had a reduction of at least one New York Heart Association (NYHA) functional class after six months of therapy $(P=0.014)$. The survival rate after 72 months was $45 \%$.

Conclusion: This study showed clinical improvement and a nonsignificant survival rate in patients with CCC after the use of CRT.

Keywords: Chagas Disease. Cardiac Resynchronization Therapy. Heart Failure.

\begin{tabular}{|c|c|c|c|}
\hline \multicolumn{4}{|c|}{ Abbreviations, acronyms \& symbols } \\
\hline ACE & $=$ Angiotensin-converting enzyme & LVESV & $=$ Left ventricular end systolic volume \\
\hline $\begin{array}{l}\text { ARB } \\
\text { CARE-HF }\end{array}$ & $\begin{array}{l}=\text { Angiotensin-receptor blockers } \\
=\text { Cardiac Resynchronization-Heart Failure Trial }\end{array}$ & MADIT & $\begin{array}{l}=\text { Multicenter Automatic Defibrillator Implantation } \\
\text { Trial }\end{array}$ \\
\hline $\mathrm{CCC}$ & = Chronic Chagas cardiomyopathy & MIRACLE & $=$ Multicenter InSync Randomized Clinical Evaluation \\
\hline & $=$ Confidence interval & NHC & $=$ National Health Council \\
\hline COMPANION & $\begin{aligned}= & \text { Comparison of Medical Therapy, Pacing and } \\
& \text { Defibrillation in Heart Failure }\end{aligned}$ & $\begin{array}{l}\text { NYHA } \\
\text { PSVT }\end{array}$ & $\begin{array}{l}=\text { New York Heart Association } \\
=\text { Paroxysmal supraventricular tachycardia }\end{array}$ \\
\hline CRT & $=$ Cardiac resynchronization therapy & RAFT & $=$ Resynchronization/Defibrillation for Ambulatory \\
\hline HF & $=$ Heart failure & & Heart Failure Trial \\
\hline HR & $=$ Hazard ratio & RBBB & $=$ Right bundle branch block \\
\hline ICD & = Implantable cardioverter defibrillator & REVERSE & $=$ The Resynchronization Reverse Remodeling in \\
\hline LAFB & $=$ Left anterior fascicular block & & Systolic Left Ventricular Dysfunc \\
\hline LBBB & $=$ Left bundle branch block & VT & $=$ Ventricular tachycardia \\
\hline LVEF & $=$ Left ventricular ejection fraction & WHO & $=$ World Health Organization \\
\hline
\end{tabular}

\section{INTRODUCTION}

According to the World Health Organization (WHO), Chagas disease is an important health problem with socioeconomic impacts in many Latin-American countries ${ }^{[1]}$. Chagas disease, also known as American Trypanosomiasis, is caused by the protozoan Trypanosoma cruzi, and WHO estimates that there are approximately 8 million people infected worldwide ${ }^{[1]}$.

'Escola de Ciências Médicas, Farmacêuticas e Biomédicas of the Pontifícia Universidade Católica de Goiás (PUC-GO), Goiânia, GO, Brazil.

This study was carried out at Escola de Ciências Médicas, Farmacêuticas e Biomédicas of the Pontifícia Universidade Católica de Goiás (PUC-GO), Goiânia, GO, Brazil.

No financial support.

No conflict of interest.
It is known that only $20 \%$ to $30 \%$ of those infected with Trypanosoma cruzi will develop chronic Chagas cardiomyopathy (CCC), one of its most frequent and severe clinical forms ${ }^{[2,3]}$. This disease causes loss of myocardial contractile function, dilation of cardiac chambers, and destruction of cardiomyocytes as well as fibrosis and scars. These patients may develop arrhythmias,

Correspondence Address:

Antônio da Silva Menezes Junior

Pontifícia Universidade Católica de Goiás

Rua 95, no 99, Setor Sul - Goiânia, GO, Brazil - Zip code: 74083-100

E-mail:a.menezes.junior@uol.com.br

Article received on April 15t, 2017 Article accepted on July $9^{\text {th }}, 2017$. 
apical aneurysms, thromboembolisms, sudden death, and heart failure $(\mathrm{HF})^{[3]}$. The progression of $\mathrm{HF}$ often leads to changes in intracardiac electrical conduction, progressing with atrioventricular, intraventricular or interventricular conduction disorders ${ }^{[4]}$.

The pharmacotherapy agents used in the treatment of HF are well established and widely used ${ }^{[5]}$. Recently, in addition to pharmacotherapy, cardiac pacing has also been a treatment option with major impact on quality of life and reduction of mortality ${ }^{[6]}$.

In the last decade, several multicenter studies - such as COMPANION (Comparison of Medical Therapy, Pacing and Defibrillation in HeartFailure) ${ }^{[7]}$, CARE-HF (CardiacResynchronizationHeart Failure Trial) ${ }^{[8]}$, REVERSE (The Resynchronization Reverse Remodeling in Systolic Left Ventricular Dysfunction) ${ }^{[9]}$, MIRACLE (Multicenter InSync Randomized Clinical Evaluation) ${ }^{[10]}$, RAFT (Resynchronization/Defibrillation for Ambulatory Heart Failure Trial) [11] and MADIT (Multicenter Automatic Defibrillator Implantation Trial) ${ }^{[12]}$ - were carried out in order to elucidate the indications and guidelines for cardiac resynchronization therapy (CRT) in patients with chronic $\mathrm{HF}^{[13-15]}$. However, these studies are not specific for CCC, as this etiology is not common in the countries in which these trials were conducted.

For the use of CRT, it is necessary to identify the patients who will respond to this therapy and those who will not. Studies show that responders and nonresponders can be identified by clinical (New York Heart Association [NYHA] functional class, 6-minute walk test, peak oxygen consumption, and quality of life score) and echocardiographic (improvement in left ventricular ejection fraction [LVEF], reduction in end-diastolic and end-systolic volume, and decreasing mitral insufficiency) parameters, as the measurements of these parameters have already been used to identify responders. However, there is no consensus in the literature about the relevant responses to this therapy ${ }^{[16-22]}$.

Thus, this study aimed to analyze the long-term responses of patients with CCC using CRT and to estimate the survival rate of responder patients.

\section{METHODS}

This is an observational, cross-sectional and retrospective study. The medical records of patients with CCC who had cardiac resynchronization devices (multisite pacemakers) implanted, from June 2009 to March 2017, and who were admitted to Santa Helena's Hospital were analyzed.

This study was conducted according to the standards of the National Health Council (NHC) on research involving humans, as stated in the Resolution 446, adopted December $12^{\text {th }}, 2012^{[22]}$. In this manner, the study was approved by the Ethics Committee of the Pontifícia Universidade Católica de Goiás (CAAE 460479152 0000 0037).

Data were obtained by reviewing the electronic medical records accessed via doctor's office - 2014 program and recorded in individual files. The study sample is not probabilistic, so the records were consecutively included.

The inclusion criteria were as follows: patients of both sexes with records available; patients diagnosed with CCC and over 18 years old; patients with NYHA class II, III or IV; and patients who have been using CRT for at least six months. Patients who did not meet the inclusion criteria were excluded as well as patients with incomplete medical records.

The study variables were as follows: age; sex; CRT duration; comorbidities (hypertension, diabetes mellitus, smoking, other comorbidities, and the use of an implantable cardioverter defibrillator [ICD]); medications (including beta-blockers, angiotensin-converting enzyme [ACE] inhibitor, angiotensinreceptor blockers [ARB], loop diuretics, thiazide diuretics, spironolactone, amiodarone, and digoxin); mortality; cause of death; number of hospitalizations; NYHA functional class before and after CRT; LVEF by Simpson before and after CRT; QRS duration before and after CRT; and arrhythmias and blocks (left bundle branch block [LBBB], right bundle branch block [RBBB], and left anterior fascicular block[LAFB]).

According to Brazilian guidelines ${ }^{[6,14]}$, patients with RBBB and $\mathrm{RBBB}+\mathrm{LAFB}$ must undergo cardiac magnetic resonance or tissue Doppler echocardiography to establish the interventricular and intraventricular dyssynchrony before receiving the CRT system implant.

To classify patients as responders after six months using CRT, the criteria were as follows: 1) reduction of at least one point in NYHA class and 2) reduction of 15\% in left ventricular end systolic volume (LVESV).

\section{Statistical Analysis}

The data were collected and entered into a database using SPSS software, version 18 (SPSS Inc. Released 2009. PASW Statistics for Windows, Version 18.0. Chicago: SPSS Inc). Descriptive statistics were used to characterize the study sample.

Continuous variables were expressed as the mean \pm standard deviation. Qualitative variables were evaluated using Chi-square test. Pearson's correlation was also used to measure the degree of linear relationship between two quantitative variables.

Appropriate tests were used to compare the variables as means (Student's t-test). Survival curves were generated using the Kaplan-Meier method. The results were presented as the hazard ratio (HR) with 95\% confidence interval (95\% CI). A P value of $<0.05$ was considered significant in all tests.

\section{RESULTS}

We analyzed the medical records of 50 patients with CCC undergoing CRT, with an average CRT duration of $61.2 \pm 21.7$ months. Of the 50 patients evaluated, $56 \%$ were male and $44 \%$ were female. The mean age of the patients was $63.4 \pm 13.3$ years (Table 1).

Regarding comorbidities, $42 \%$ of the patients presented with hypertension, 18\% had diabetes mellitus, 20\% were current cigarette smokers and $46 \%$ had other comorbidities (Table 1).

Regarding medications, 64\% of patients used beta-blockers, 36\% used ACE inhibitors, 48\% used ARB, 68\% used loop diuretics or thiazide diuretics, $44 \%$ used spironolactone, $70 \%$ used amiodarone, 30\% used digoxin, and 58\% used some other drug (Table 1).

The use of ICD was reported in $74 \%$ of patients (Table 1). These patients had indications for the use of ICD before CRT, 
Table 1. Patients' characteristics.

\begin{tabular}{|c|c|c|c|c|}
\hline \multicolumn{2}{|l|}{ Characteristics } & \multirow{2}{*}{$\frac{\text { No. (\%) }}{22(44)}$} & \multirow[t]{2}{*}{ Mean } & \multirow[t]{2}{*}{ Standard Deviation } \\
\hline Soy & Female & & & \\
\hline sex & Male & $28(56)$ & & \\
\hline Age (years) & & & 63.4 & 13.3 \\
\hline \multirow{13}{*}{ Personal history } & Hypertension & $21(42)$ & & \\
\hline & Diabetes mellitus & $9(18)$ & & \\
\hline & Current cigarette smoking & $10(20)$ & & \\
\hline & Chronic kidney disease & $6(12)$ & & \\
\hline & Coronary artery disease & $5(10)$ & & \\
\hline & Hypothyroidism & $4(8)$ & & \\
\hline & Previous stroke & $2(4)$ & & \\
\hline & Hypercholesterolemia & $1(2)$ & & \\
\hline & Megacolon & $1(2)$ & & \\
\hline & Megaesophagus & $1(2)$ & & \\
\hline & $\begin{array}{l}\text { Chronic obstructive pulmonary } \\
\text { disease }\end{array}$ & $1(2)$ & & \\
\hline & Polyneuropathy & $1(2)$ & & \\
\hline & Epilepsy & $1(2)$ & & \\
\hline \multirow{8}{*}{ Medication } & Beta-blockers & $32(64)$ & & \\
\hline & ACE inhibitor & $18(36)$ & & \\
\hline & $A R B$ & $24(48)$ & & \\
\hline & Spironolactone & $22(44)$ & & \\
\hline & Loop diuretics/thiazide & $34(68)$ & & \\
\hline & Amiodarone & $35(70)$ & & \\
\hline & Digoxin & $15(30)$ & & \\
\hline & Others & $29(58)$ & & \\
\hline \multirow{2}{*}{ Mortality } & Cardiovascular cause & $7(14)$ & & \\
\hline & Other causes & $6(12)$ & & \\
\hline CRT use duration (months) & & & 61.2 & 21.7 \\
\hline ICD use & & $37(74)$ & & \\
\hline
\end{tabular}

$\mathrm{ACE}=$ angiotensin-converting enzyme; $\mathrm{ARB}=$ angiotensin-receptor blockers; $C R T=c a r d i a c$ resynchronization therapy;

$I C D=$ implantable cardioverter defibrillator

such as the presence of complex ventricular arrhythmias, results of electrophysiological study and secondary prevention.

The electrophysiological disturbances, like the presence of arrhythmias and bundle branch blocks, are shown in Table 2. Arrhythmias were identified in patients; nonsustained ventricular tachycardia (VT) was the most frequently observed arrhythmia (22\% of patients), followed by paroxystic atrial fibrillation/ paroxysmal supraventricular tachycardia (PSVT) (14\%) and sustained VT (6\%).

Sixty percent of the patients had LBBB, while 10\% had RBBB; $30 \%$ of the patients had RBBB associated with LAFB. The expressive number of LBBB is due to dual chamber pacing patients which had done an upgrade to biventricular pacing (30\%). Only 8 out of 30 patients with LBBB $(33,3 \%)$ did not exhibit a CRT response. Additionally, 2 out of 5 patients with RBBB (40\%) did not also exhibit a CRT response and 7 out of the 15 patients with RBBB + LAFB $(46,6 \%)$ were also considered nonresponders.

The average QRS durations were $150.12 \pm 12.4 \mathrm{~ms}$ and $116.04 \pm 2.24 \mathrm{~ms}$ before and after CRT, respectively, showing a statistically significant difference $(P<0.001)$. Only $1(2 \%)$ patient presented a narrow QRS complex (QRS = $139 \mathrm{ms)}$ before and after therapy. A total of $26(52 \%)$ patients who had presented with a wide QRS complex (QRS >150 ms) before CRT exhibited a change to a narrow QRS complex (QRS $<120 \mathrm{~ms}$ ) after CRT. 
Table 2. Electrophysiological disturbances of the patients.

\begin{tabular}{|c|c|c|c|c|}
\hline Type & & $\begin{array}{c}\text { Frequency } \\
\text { No. (\%) }\end{array}$ & $\begin{array}{c}\text { Frequency of } \\
\text { responders } \\
\text { No. }(\%)\end{array}$ & $\begin{array}{c}\text { Frequency of } \\
\text { nonresponders } \\
\text { No. (\%) }\end{array}$ \\
\hline \multirow{6}{*}{ Arrhythmia } & Ventricular arrhythmia & $2(4)$ & $2(4)$ & - \\
\hline & Paroxistic atrial fibrillation/PSVT & $7(14)$ & $5(10)$ & $2(4)$ \\
\hline & Atrial flutter & $1(2)$ & - & $1(2)$ \\
\hline & Sustained VT & $3(6)$ & $3(6)$ & - \\
\hline & Nonsustained VT & $11(22)$ & $7(14)$ & $4(8)$ \\
\hline & Not reported & $26(52)$ & $22(44)$ & $4(8)$ \\
\hline \multirow{4}{*}{ Blocks } & RBBB & $5(10)$ & $3(60)$ & $2(40)$ \\
\hline & LBBB & $15(30)$ & $12(80)$ & $3(20)$ \\
\hline & LBBB (dual chamber pacing) & $15(30)$ & $10(66.6)$ & $5(33.3)$ \\
\hline & $\mathrm{RBBB}+\mathrm{LAFB}$ & $15(30)$ & $8(53.3)$ & $7(46.6)$ \\
\hline
\end{tabular}

LAFB=left anterior fascicular block; LBBB=left bundle branch block; PSVT=paroxysmal supraventricular tachycardia; RBBB=right bundle branch block; $\mathrm{VT}=$ ventricular tachycardia

Table 3. Left ventricular ejection fraction before and after CRT use.

\begin{tabular}{l|c|c|c}
\hline LVEF & Mean & Standard Deviation & P Value * \\
\hline Before CRT & $29 \%$ & 7 & \\
\hline After CRT & $39.9 \%$ & 13.1 & $<0.001$ \\
\hline
\end{tabular}

CRT=cardiac resynchronization therapy; LVEF=left ventricular ejection fraction

*P value estimated by Student's t-test.

However, despite this change, 5 of these patients (10\%) were considered nonresponders.

The mean LVEF before CRT was 29 \pm 7\% and the mean LVEF after CRT was $39.9 \pm 13.1 \%$, indicating a statistically significant increase in LVEF after CRT $(P<0.001)$ (Table 3). Differently, the LVESV before CRT was $265 \pm 59 \mathrm{ml}$ and the mean LVESV after CRT was $152 \pm 59 \mathrm{ml}(P<0.01)$. The mean LVEF of the patients stratified by electrogram abnormalities ( $L B B B, R B B B$, and $R B B B+L A F B$ ) before and after CRT are shown in Figure 1.

With the implementation of CRT, there was a significant improvement in the NYHA functional class. As shown in Figure 2, the proportion of patients in NYHA classes III and IV decreased after 24 months of CRT (from 68 to $12 \%$ and from 14 to $6 \%$, respectively) ( $P=0.014)$. Due to variations in CRT use duration, the data from 24 months onwards does not correspond to the total number of patients in the study, although there is a significant improvement in NYHA class variation over this time.

Based on evaluation of the improvement in functional class and LVESV individually, $66.6 \%$ of patients showed improvement in functional class after six months of CRT. However, $33.3 \%$ did not exhibit any change in functional class and LVESV after six months of CRT.

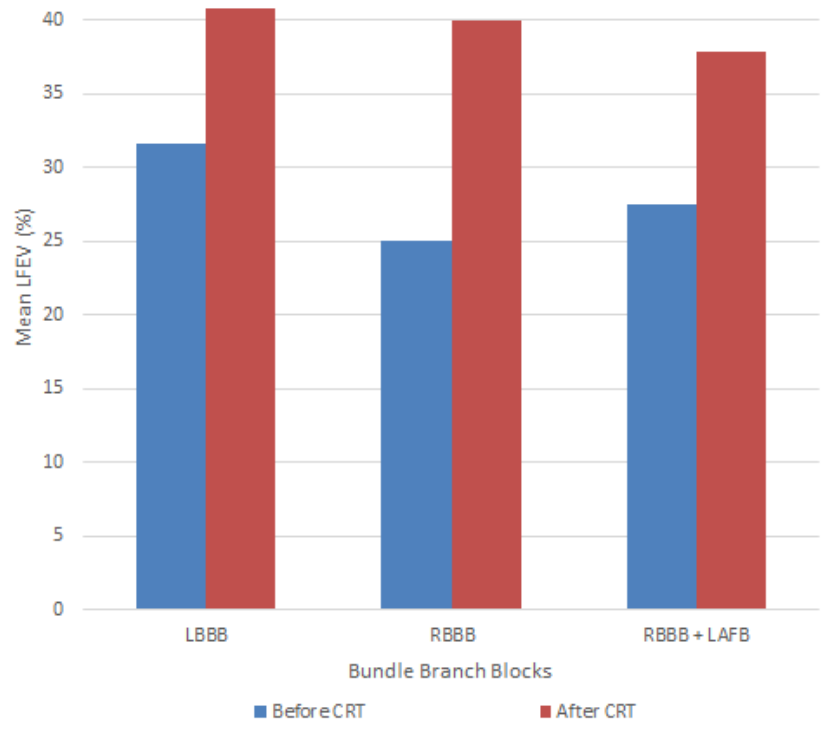

Fig. 1 - Mean left ventricular ejection fraction (LVEF) according to the bundle branch blocks presented by the patients before and after cardiac resynchronization therapy (CRT).

$\angle A F B=$ left anterior fascicular block; $\angle B B B=$ left bundle branch block; $R B B B=$ right bundle branch block

During the use of CRT, $46 \%$ of responder patients required hospitalization, with an average of $1.5( \pm 2.2)$ hospitalizations. The following were the main causes of hospitalization presented by the patients in the study: ventricular arrhythmias, atrial arrhythmias, HF exacerbation, appropriate and inappropriate ICD therapies, pneumonia, chronic obstructive pulmonary disease, urinary tract infection, and decompensation of diabetes mellitus.

Death occurred in 25 responder patients (45\%), 18 due to cardiovascular causes and 7 due to other causes (Table 1). Among 


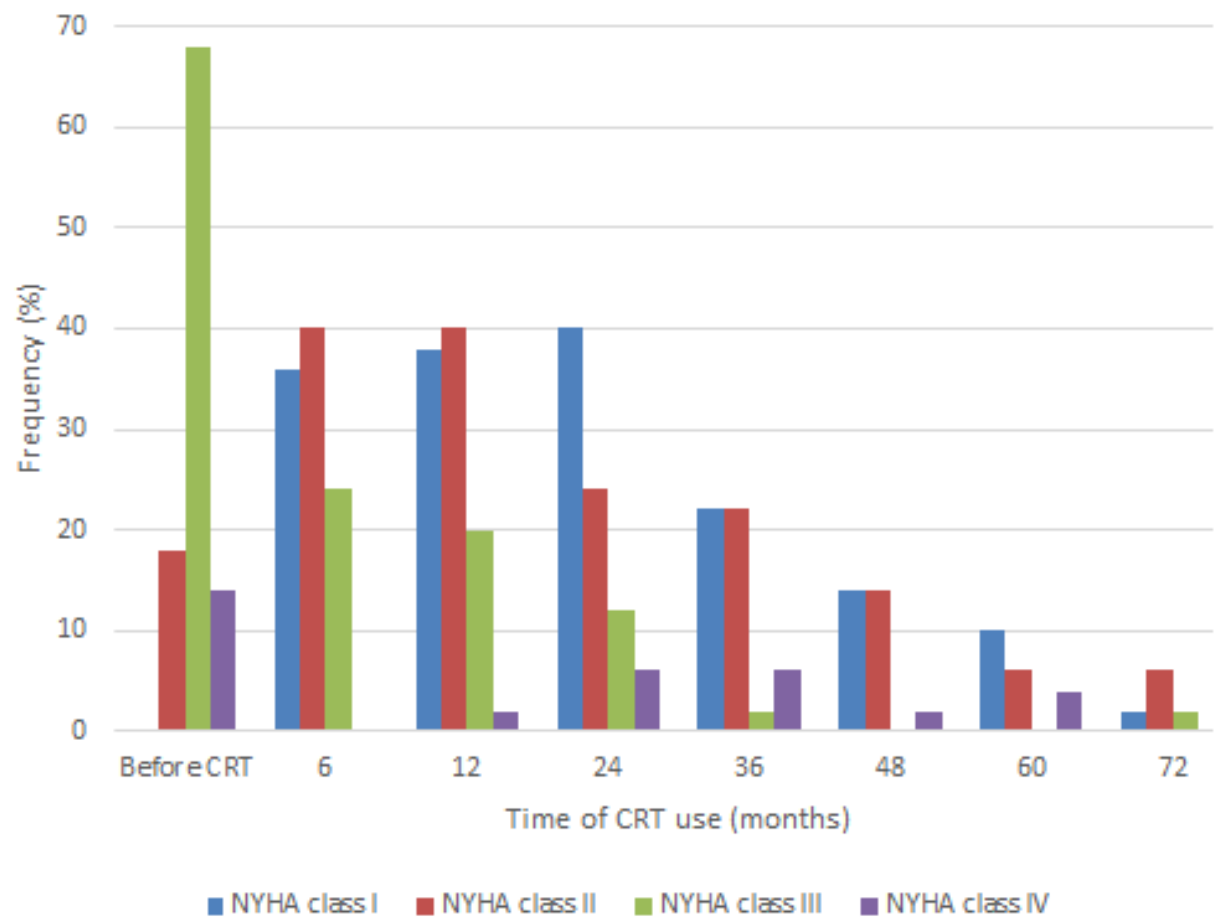

Fig. 2 - Variation of New York Heart Association (NYHA) functional class presented by the patients over the cardiac resynchronization therapy (CRT) duration.

the cardiovascular causes of death were arrhythmias (6\%), stroke (2\%), acute coronary syndrome (2\%), and decompensation of congestive HF (acute pulmonary edema) (4\%).

The overall survival rate of responder patients estimated by the Kaplan-Meier method was $100 \%$ at 12 months and approximately $45 \%$ at 72 months. In the analysis adjusted by age ( $<40$ years and $\geq 40$ years), the survival rate was the same in both groups; therefore, there was no difference in response to the therapy due to age. However, no individuals under 40 years old had used CRT for 60 months (Figure 3).

\section{DISCUSSION}

In our study, $56 \%$ of the patients were male, with mean age of 63.4 years, as observed in the literature. One study presented a higher percentage of males, with mean age ranging from 57.6 to 67.8 years. In another study, the mean age ( $53 \pm 12.1$ years) was significantly lower in patients with Chagas disease than in those with other etiologies $(P<0.001)^{[23-25]}$.

In the literature, the main heart conditions associated with CCC are complex ventricular arrhythmias; co-occurring tachyarrhythmias and bradyarrhythmias; and biventricular HF[23]. There is also a combination of LBBB and LAFB that is quite typical of CCC ${ }^{[3]}$. In our study, $48 \%$ of patients showed some arrhythmia, with 22\% exhibiting nonsustained VT and 6\% exhibiting sustained VT. Regarding blocks, 20\% had RBBB, 46\% had LBBB, and $32 \%$ had RBBB+LAFB.

Studies estimate that a QRS duration of $\geq 120$ ms occurs in $25-50 \%$ of patients with HF[26,27]. In the present study, $98 \%$ of patients already had a QRS duration of $>150$ ms before the use of
CRT, with an average QRS duration of 150.12 ms. After the use of CRT, that average dropped to $116.04 \mathrm{~ms}$, a significant difference $(P<0.001)$ following large studies, such as COMPANION and MADIT-CRT, and showing that patients with a long QRS duration benefit from $C R T^{[7,12]}$.

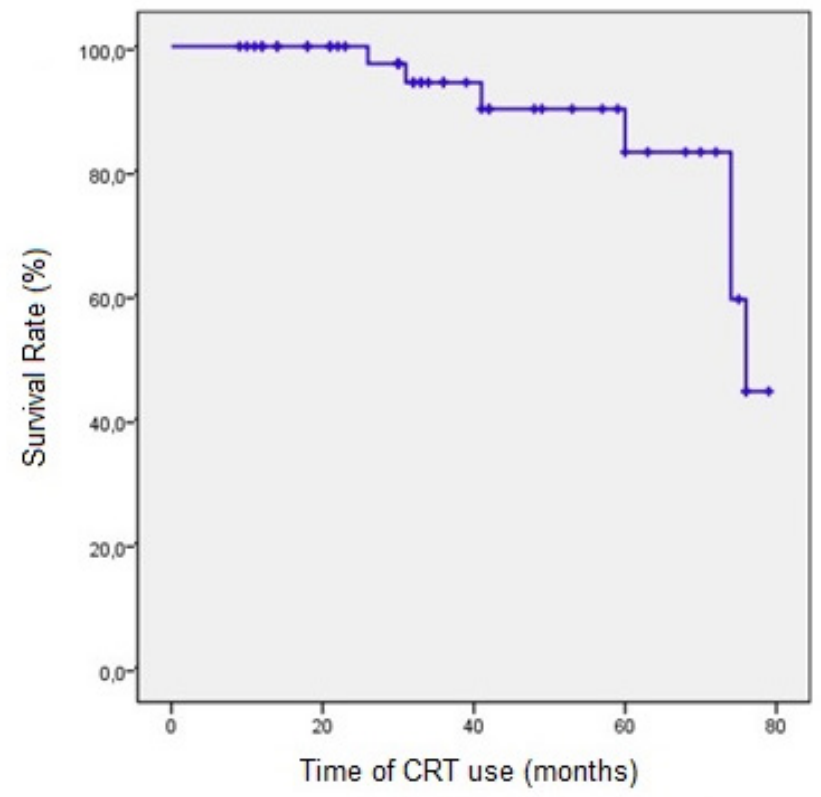

Fig. 3 - Kaplan-Meier estimates of survival for cardiac resynchronization therapy (CRT) responder patients. 
Our study showed that $33.3 \%$ of patients did not respond to CRT. A study of 72 patients with CCC showed that $65.3 \%$ of them responded to CRT at the end of a follow-up ranging from 4 to 79 months ${ }^{[25]}$. Another study evaluating the use of CRT in patients with CCC reported that $95.3 \%$ of them (20 patients) were responders and that only $4.7 \%$ of patients ( 1 patient) did not respond to the therapy ${ }^{[28,29]}$.

Several studies consider NYHA functional class as an evaluation parameter of the response to $C R T^{[30]}$. In our study, variations of NYHA class over time showed that before CRT, 68\% of patients were in NYHA class III, 18\% in NYHA class II and 14\% in NYHA class IV. After six months of CRT use, only $22 \%$ of patients (11 patients) showed no improvement in functional class. A study of the use of CRT in 21 patients with CCC, with a follow-up of over 18 months, showed that $85.7 \%$ of patients had improvements in functional class ${ }^{[31]}$. In the study by Martinelli Filho et al..25], 83.8\% of patients showed improvement by at least one functional class, while 16.2\% remained in the same functional class or worsened it.

In the study of Araújo et al.[3], it was possible to verify clinical benefits of the use of CRT in patients with CCC and at the end of their follow-up, they showed statistically significant improvements in functional class and LVEF as well as reduced left ventricular diameter and end-systolic volume, in agreement with our results.

Our study showed a significant increase in the mean LVEF before and after the use of CRT. In agreement with our finding, other studies also showed a significant increase in this parameter ${ }^{[28,31]}$.

A systematic review of predictors of mortality in CCC revealed that symptoms of HF (NYHA class III/IV), left ventricular impairment on echocardiography, cardiomegaly on chest radiography and nonsustained VT events in Holter are factors associated with the risk of death or a worse prognosis; therefore, these symptoms require stricter interventions ${ }^{[23]}$.

In our study, the survival rate after 72 months of CRT was $45 \%$, which was lower than the rate of $50 \%$ estimated in the literature after 60 months from the diagnosis of $\mathrm{HF}^{[14,32,33] \text {. }}$

Several studies have shown that up to two-thirds of patients with $\mathrm{HF}$ are hospitalized on average twice a year, and the rate of rehospitalization within 3 months reaches $20-30 \%{ }^{[34]}$. In our study, the number of hospitalizations was not related to the CRT use duration $(P=0.548)$, but it was significantly inversely associated with cardiovascular cause of death $(P<0.001)$.

Another study of the use of CRT with or without ICD showed significant benefits of the isolated use of CRT and ICD in HF. However, the effect of the combination of these therapies is not well established as the study data are still insufficient ${ }^{[35]}$.

Rassi et al.[23] state that one of the main causes of death in Chagas disease is HF. In a study of CCC patients using CRT with long-term follow-up, the overall mortality was 34.7\% (25 patients). Of these deaths, $76 \%$ were due to cardiovascular causes, $8.3 \%$ due to non-cardiovascular causes and $16 \%$ due to unknown causes. The worsening of HF was the main cause of death among the cardiovascular causes (60\% of the cases), in agreement with our results ${ }^{[31]}$.

Martinelli Filho et al. ${ }^{[25]}$ showed that, at the end of the proposed follow-up, 97 (28.2\%) deaths were recorded, corresponding to an annual mortality of $6.7 \%$. The cardiac cause was the main cause of death, corresponding to $84.5 \%$ of the known causes. The authors noted that this increased mortality may have been related to the high number of patients with advanced atrioventricular block, and they state that although CRT has a positive impact on the clinical behavior of patients with CCC, the long-term prognosis is worse compared to other heart diseases ${ }^{[2]}$.

\section{Limitations}

Our study has some limitations. First, it was a single-center study that included a limited number of patients. Furthermore, being a retrospective study, the data were derived from medical records, however, all patients in accordance with inclusion criteria were studied.

\section{CONCLUSION}

This study revealed that a relevant number of patients with CCC using CRT has been considered as CRT responders (reduction of the NYHA functional class and reduction of LVESV), otherwise, these patients had no significant improvements in survival rates after 72 months.

\section{Authors' roles \& responsibilities}

ASMJ Designed the study and performed the experiments and wrote the manuscript; final approval of the version to be published

CCL Designed the study and performed the experiments and wrote the manuscript; final approval of the version to be published

PFC Performed the experiments; final approval of the version to be published

EM Analyzed the data; final approval of the version to be published

\section{REFERENCES}

1. Ciapponi A, Alcaraz A, Calderón M, Matta MG, Chaparro M, Soto N, et al. Burden of heart failure in latin america: a systematic review and meta-analysis. Rev Esp Cardiol (Engl Ed). 2016;69(11):1051-60.

2. Bello Corassa R, Aceijas C, Alves PAB, Garelick H. Evolution of Chagas' disease in Brazil. Epidemiological perspective and challenges for the future: a critical review. Perspect Public Health. 2017;137(5):289-95.

3. Rassi A Jr, Rassi A, Marin-Neto JA. Chagas disease. Lancet. 2010;375(9723):1388-402.

4. Vardas PE, Auricchio A, Blanc JJ, Daubert JC, Drexler H, Ector H, et. al. Guidelines for cardiac pacing and cardiac resynchronization therapy: The Task Force for Cardiac Pacing and Cardiac Resynchronization Therapy of the European Society of Cardiology. Developed in collaboration with the European Heart Rhythm Association. Eur Heart J. 2007;28(18):2256-95.

5. Bestetti RB, Theodoropoulos TA, Cardinalli-Neto A. Treating patients with Chagas' cardiomyopathy with chronic heart failure in the contemporary era. Am Heart J. 2007;154(5):e35.

6. Martinelli Filho M, Zimerman LI, Lorga AM, Vasconcelos JTM, Rassi A Jr. Guidelines for implantable electronic cardiac devices of the Brazilian Society of Cardiology. Arq Bras Cardiol. 2007;89(6):e210-38.

7. Bristow MR, Saxon LA, Boehmer J, Krueger S, Kass DA, De Marco T, et 
al. Cardiac-resynchronization therapy with or without an implantable defibrillator in advanced chronic heart failure. $\mathrm{N}$ Engl J Med. 2004:350(21):2140-50.

8. Cleland JG, Daubert JC, Erdmann E, Freemantle N, Gras D, Kappenberger $L$, et al. Longer-term effects of cardiac resynchronization therapy on mortality in heart failure [the CArdiac REsynchronization-Heart Failure (CARE-HF) trial extension phase]. Eur Heart J. 2006;27(16):1928-32.

9. Daubert C, Gold MR, Abraham WT, Ghio S, Hassager C, Goode G, et al. Prevention of disease progression by cardiac resynchronization therapy in patients with asymptomatic or mildly symptomatic left ventricular dysfunction: insights from the European cohort of the REVERSE (Resynchronization Reverses Remodeling in Systolic Left Ventricular Dysfunction) trial. J Am Coll Cardiol. 2009;54(20):1837-46.

10. Young JB, Abraham WT, Smith AL, Leon AR, Lieberman R, Wilkoff B, et al; Multicenter InSync ICD Randomized Clinical Evaluation (MIRACLE ICD) Trial Investigators. Combined cardiac resynchronization and implantable cardioversion defibrillation in advanced chronic heart failure: the MIRACLE ICD Trial. JAMA. 2003;289(20):2685-94.

11. Tang AS, Wells GA, Talajic M, Arnold MO, Sheldon R, Connolly S, et al. Cardiac-resynchronization therapy for mild-to-moderate heart failure. N Engl J Med. 2010;363(25):2385-95.

12. Moss AJ, Hall WJ, Cannom DS, Klein H, Brown MW, Daubert JP, et al; MADIT-CRTTrial Investigators. Cardiac-resynchronization therapy for the prevention of heart-failure events. N Engl J Med. 2009;361(14):1329-38.

13. Silva RT, Martinelli Filho M, Lima CE, Martins DG, Nishióka SA, Pedrosa AA, et al. Functional behavior of patients with conventional pacemakers undergoing cardiac resynchronization. Arq Bras Cardiol. 2008;90(2):13843.

14. Fuganti CJ, Melo CS, Moraes Jr AV, Pachon-Mateos JC, Pereira WL, Galvão Filho SS, et al.; Departamento de Estimulação Cardíaca Artificial da Sociedade Brasileira de Cirurgia Cardiovascular. Diretrizes: Cardiodesfibrilador implantável; infecção em DCEl; papel dos fármacos antiarrítmicos; direção veicular em portadores de DCEl. [accessed: 2016 Jan 21]. Available from: http://www.deca.org.br/Medica/arquivos/ SuplementoRelampa.pdf

15. Tracy CM, Epstein AE, Darbar D, Dimarco JP, Dunbar SB, Estes NA 3rd, et al. 2012 ACCF/AHA/HRS focused update of the 2008 guidelines for devicebased therapy of cardiac rhythm abnormalities: a report of the American College of Cardiology Foundation/American Heart Association Task Force on Practice Guidelines. J Am Coll Cardiol. 2012;60(14):1297-313.

16. Dickstein K, Vardas PE, Auricchio A, Daubert JC, Linde C, McMurray J, et al. 2010 Focused Update of ESC Guidelines on device therapy in heart failure: an update of the 2008 ESC Guidelines for the diagnosis and treatment of acute and chronic heart failure and the 2007 ESC guidelines for cardiac and resynchronization therapy. Developed with the special contribution of the Heart Failure Association and the European Heart Rhythm Association. Eur Heart J. 2010;31(21):2677-87.

17. Fornwalt BK, Sprague WW, BeDell P, Suever JD, Gerritse B, Merlino JD, et al. Agreement is poor among current criteria used to define response to cardiac resynchronization therapy. Circulation. 2010;121(18):1985-91.

18. Chung ES, Leon AR, Tavazzi L, Sun JP, Nihoyannopoulos P, Merlino J, et al. Results of the Predictors of Response to CRT (PROSPECT) trial. Results of the Predictors of Response to CRT (PROSPECT) trial. Circulation. 2008;117(20):2608-16.

19. Gorcsan J 3rd, Oyenuga O, Habib PJ, Tanaka H, Adelstein EC, Hara H, et al. Relationship of echocardiographic dyssynchrony to long-term survival after cardiac resynchronization therapy. Circulation. 2010;122(19):1910-8.

20. Bax JJ, Gorcsan J 3rd. Echocardiography and noninvasive imaging in cardiac resynchronization therapy: results of the PROSPECT (Predictors of Response to Cardiac Resynchronization Therapy) study in perspective. J Am Coll Cardiol. 2009;53(21):1933-43.

21. White JA, Yee R, Yuan XP, Krahn A, Skanes A, Parker M, et al. Delayed enhancement magnetic resonance imaging predicts response to cardiac resynchronization therapy in patients with intraventricular dyssynchrony. J Am Coll Cardiol. 2006;48(10):1953-60.

22. Køber L, Thune JJ, Nielsen JC, Haarbo J, Videbæk L, Korup E, et al; DANISH Investigators. Defibrillator implantation in patients with nonischemic systolic heart failure. N Engl J Med. 2016;375(13):1221-30.

23. Rassi A Jr, Rassi A, Rassi SG. Predictors of mortality in chronic Chagas disease: a systematic review of observational studies. Circulation. 2007;115(9):1101-8.

24. Ruschitzka F, Abraham WT, Singh JP, Bax JJ, Borer JS, Brugada J, et al. Cardiac-resynchronization therapy in heart failure with a narrow QRS complex. N Engl J Med. 2013;369(15):1395-405.

25. Martinelli Filho M, Peixoto GL, Siqueira SF, Martins SAM, Nishioka SAD, Costa $\mathrm{R}$, et al. Terapia de ressincronização cardíaca na cardiomiopatia chagásica crônica: boa resposta clínica e pior prognóstico. Relampa. 2013;26(1):33-8.

26. Silva Menezes A. Outcome of right ventricular bifocal pacing in patients with permanent atrial fibrillation and severe dilated cardiomiopathy due to Chagas disease: three years of follow-up. J Interv Card Electrophysiol. 2004;11(3):193-8.

27. Wikstrom G, Blomström-Lundqvist C, Andren B, Lönnerholm S, Blomström P, Freemantle N, et al; CARE-HF study investigators. The effects of aetiology on outcome in patients treated with cardiac resynchronization therapy in the CARE-HF trial. Eur Heart J. 2009;30(7):782-8.

28. Pereira FTM, Rocha EA, Monteiro MPM, Rocha Neto AC, Daher EF, Rodrigues Sobrinho CRM, et al. Long-term follow-up of patients with chronic chagas disease and implantable cardioverter-defibrillator. Pacing Clin Electrophysiol. 2014;37(6):751-6.

29. Bestetti RB. Cardiac resynchronization therapy for patients with chronic systolic heart failure secondary to Chagas cardiomyopathy in the 21st century. Rev Bras Cir Cardiovasc. 2014;29(1):IV-VI.

30. Tian Y, Zhang P, Li X, Gao Y, Zhu T, Wang L, et al. True complete left bundle branch block morphology strongly predicts good response to cardiac resynchronization therapy. Europace. 2013;15(10):1499-506.

31. Araújo EF, Chamlian EG, Peroni AP, Pereira WL, Gandra SM, Rivetti $L A$, et al. Cardiac resynchronization therapy in patients with chronic Chagas cardiomyopathy: long-term follow up. Rev Bras Cir Cardiovasc. 2014;29(1):31-6.

32. Cleland JG, Abraham WT, Linde C, Gold MR, Young JB, Claude Daubert J, et al. An individual patient meta-analysis of five randomized trials assessing the effects of cardiac resynchronization therapy on morbidity and mortality in patients with symptomatic heart failure. Eur Heart J. 2013;34(46):3547-56.

33. Abraham WT, Fisher WG, Smith AL, Delurgio DB, Leon AR, Loh E, et al; MIRACLE Study Group. Multicenter InSync Randomized Clinical Evaluation. Cardiac resynchronization in chronic heart failure. N Engl J Med. 2002;346(24):1845-53.

34. Nunes MC, Dones W, Morillo CA, Encina JJ, Ribeiro AL; Council on Chagas Disease of the Interamerican Society of Cardiology. Chagas disease: an overview of clinical and epidemiological aspects. J Am Coll Cardiol. 2013;62(9):767-76.

35. Kalil C, Nery PB, Bartholomay E, Albuquerque LC. Tratamento com cardioversor-desfibrilador implantável e ressincronização cardíaca: isolados ou associados? Rev Bras Cir Cardiovasc. 2006;21(1):85-91. 